Conclusion Challenging the traditional 'chaplaincy' role, creating a new model of care to match the changes in the local communities and across the country, has been a huge transformation within the organisation. Our new Spiritual Care Specialist will ensure our organisation is fully inclusive, meeting the needs of all Rowcroft patients, relatives, carers, staff and volunteers.

\section{P-235 EVOLUTION IN THE TEAM, REVOLUTION IN THE SERVICE}

Jo Ansell. Garden House Hospice Care, Letchworth, UK

10.1136/bmjspcare-2019-HUKNC.257

Background We are a family support team of 4.68 WTE paid staff made up of counsellors, a social worker, spiritual care co-ordinator, administrator and 25 volunteers. A new manager was appointed in late 2017 and found a team struggling under a long waiting list. Feedback from other teams in the hospice was frustration that family support was slow and unresponsive.

Aims Following a team away day in January 2018 we decided to re-focus our work to be:

- timely and appropriate;

- rehabilitative and empowering;

- efficiently supported and evaluated.

We had no specific numeric goals at this point, only to reduce our waiting list and become more responsive.

Method Taking a whole-system approach devised a plan which included major changes to:

- Team ethos;

- Assessment and referral processes;

- Communication and roles;

- Our counselling/service model;

- Recruitment and training;

- Evaluation and data collection.

Results After a year we achieved and have maintained:

- The elimination of our waiting list; clients are now allocated within days of being assessed unless they have very limited available time slots;

- Response to tasks and requests within two working days, usually within 24 hours;

- Positive outcomes demonstrated in self-reported evaluation and improved Core 10 scores.

Conclusion

- A whole team/whole system approach fostered a commitment to our aims and acceptance of the changes we needed to make, even when they were difficult;

- A short-term counselling model is appropriate in a hospice setting if supported by theoretical and practical training in how to deliver counselling in this way;

- The no-waiting approach means that the intervention is made when it is needed and can be most effective, and our outcome results show this;

- Our willingness to be flexible in the way we work with individual cases where specific need is demonstrated provides the team with confidence that we remain client centred within a rehabilitative model.

\section{P-236 WIRRAL HOSPICE ST JOHN'S TEMPORARY VOLUNTEER BENEFITS ADVISOR SERVICE}

James George. Wirral Hospice St John's, Bebington, UK

\subsection{6/bmjspcare-2019-HUKNC.258}

Background The Wirral Hospice understands the need for expert benefits advice and guidance to assist and support patients and carers to maximise income and reduce hardship. We set up and audited a volunteer benefits advisor service at the hospice and its effectiveness over an 18month period.

Aim The audit of a new temporary volunteers benefits advisor service (unpaid specialist advisor) via appointments with patients/carers and to assess benefit of specialist intervention.

Method Quantitative data collection. Via referrals, intervention and outcomes measures -Benefits correct, Benefits gain and Benefits overpayment, use of DS1500, and referral to third party agencies. The average number of referrals were 3-4 patients/carers PW during an 18 month period. Over $110+$ patients took part.

Results

- The evidence showed that the service prompted a financial gain for many patients and carers, which was around $64 \%$;

- Financial gain is not the only measure in value - patients/ carers found reassurance that their benefit was correct. It gave the opportunity for some families to discuss future financial position if a person dies;

- The timely use of DS1500 was very important to avoid people missing out on their entitlement. $21 \%$ of patients were issued a DS1500 as they met criteria and were not receiving higher/enhanced rates of disability payment;

- $10 \%$ of patients/carer were referred on for complex issues requiring paid skilled benefit advisors.

Conclusion It was established that the benefit to patient/carers were considerable based on audit. The service needs to grow and move to a day time provision which would allow for the provision of benefits awareness sessions for staff and volunteers. We have agreed a four-hour weekly $\mathrm{CAB}$ provision at the hospice to start September 2019.

\section{P-237 A SURVEY OF PSYCHOLOGICAL SUPPORT SERVICES IN UK HOSPICES: WHO, WHAT, WHERE AND HOW?}

Daisy McInnerney, Nuriye Kupeli, Patrick Stone, Bridget Candy. Marie Curie Palliative Care Research Department, Division of Psychiatry, UCL, London, UK

\subsection{6/bmjspcare-2019-HUKNC.259}

Background People receiving end-of-life care and their family carers can experience significant psychological distress (Wilson, Chochinov, Graham Skirko, Allard et al., 2007; Galfin \& Watkins, 2012; Braun, Mikulincer, Rydall, Walsh et al., 2007; Grov, Dahl, Moum, Fosså, 2005). Psychological support is a fundamental aspect of the holistic care provided by hospices (NHS. Hospice care [Internet], 2017; NHS England, 2019). However, there are limited clinical guidelines in the UK on how hospices should deliver psychological support services (National Institute for Health and Care Excellence, 2017). No recent research has explored how psychological services are delivered in UK hospices on a national level. A nationwide 